\title{
Terminological Network Application to the Construction of an Expert System of Academic Knowledge Representation
}

\author{
Latu M.N. ${ }^{1}$ Tagiltseva Yu.R.,"* \\ ${ }^{1}$ Pyatigorsk State University, Pyatigorsk, Russia \\ ${ }^{2}$ Ural state pedagogical University, Yekaterinburg, the Russia \\ *Corresponding author. Email: jennifer1979@yandex.ru
}

\begin{abstract}
There have been experience of using terminology network described in the article. Experience of using terminology network is considered to be a cognitive model for representing scientific knowledge to create an expert system of the subject area. The authors substantiate the role and specificity of expert systems in the era of digitalization of various spheres of human activity, including scientific and professional, describe the essence of the network model, which can be the basis of the systematization of knowledge and terminological network, in particular, which is a kind of semantic network and serves for modeling organization of concepts in a specific scientific or professional sphere.

Peculiarities of the terminology network in terms of storage, system representation and processing elements of scientific knowledge are considered in the article, as well as its capabilities in relation to the selected list of tasks that are solved by expert system. There have been essence and specifics of each of the developed modes of its functioning described , including the modes "Ask a question", "Compare", "Search by attributes", "Look in the dictionary", "Share an idea", and if you have administrator rights you can use the "Editor"mode.

The latter is used for storing concepts in the database, system connections with related concepts (taking into account principles of constructing terminology networks developed by us), and information related to each concept that is necessary for the correct output of desired data. The features of navigation system between modes are revealed. The authors give accent to significance of correlation of different types of system relations and output response formulations for the operation of different modes, making a dialogue with the expert system, comparing knowledge elements and searching based on the specified information.
\end{abstract}

Keywords: cognitive model, expert system, systemic relation, terminological network, technical term

\section{INTRODUCTION}

Nowadays digitalization plays a significant role in development of scientific and technological progress, storage, systematization and obtaining necessary information. Currently existing models of knowledge representation are characterized by a variety of construction principles, functionality, and tasks to be solved. These models can be used to create expert systems, which are computer programs that reproduce the way an expert solves a problem [Grabinger, Wilson, Jonassen 1990] and can also be used to obtain new knowledge in the process of self-education.

Specifics of expert system primarily lies in the fact that it accumulates specialists' knowledge various fields in order to carry out the study of a particular problem, based on the information already contained in the system. Ajit Abraham and P. N. Semchenko, following J. P. Ignizio, highlight such important advantages in comparison with conventional computer programs as, at first, the ability to solve various problems in the same knowledge base using the same program without any expenses on reprogramming, and secondly, to disclose the track of reasoning. All this makes it possible to quickly obtain information, establish connections with the database to get answers, forecasts and assumptions, and the logical inference mechanism finds the correct facts, rules, and interpretations and composes them in the right way [Ignizio 1991; Ajit Abraham, Semchenko 2013]. According to I. M. Ahmed, A. M. Mahmoud, M. Aref and A.-B. M. Salem, expert systems currently "solve partially or completely a significant problem" in various subject areas and "reduce the urgent need for human experts" [Ahmed, Alfonse, Aref, Salem 2013]. 


\section{PROBLEM STATEMENT, METHODS}

Semantic network is a network of concepts expressed in separate words and phrases, which together with connections between such concepts form its structure [Carley, 1997; Doerfel, 1998; Diesner 2013], which makes them fairly convenient, since they can give a complete picture of correlation of components of a certain area [Allemang, Hendler, 2011]. These relationships reveal different nature of vertex correlation [Faber, Leon, Prieto, 2009]. It is worth noting that these relationships, as believed by N. V. Basov and V. V. Vasilkova, after K. Carly, are established within the framework of collocation analysis - by the spatial proximity corresponding words in the text that represents their associative relationship. All this gives an opportunity to study characteristics of knowledge, identify various relationships between thousands of concepts, fix dominant positions and reveal their content, which is set in a text [Basov, Vasilkova 2014].

Therefore, semantic networks are irreplaceable when you need super-precision information processing, system representation of knowledge. After all, as D.Ustalov notes, their competitive advantages are in solving such problems as resolution of lexical polysemy, which allows you to determine specific meaning of each word used in the text under study; creating derivative lexical-semantic resources; marking objects in depictions; object or semantic search for factual information [Ustalov 2017]. And it is equally important that all models of semantic network are customizable for any specific subject area, that makes them universal [Ayusheeva, Wilyk 2018].

Terminological network is a special case of semantic network and it systemically represents specifics of organization of scientific knowledge. The vertices of such a network are concepts and terms that express them; the connections between the vertices demonstrate the semantic relationships between them [Latu, 2017; Latu, 2018].

At the same time, it is important to note the need to classify vertices into categories that correspond to typology of scientific concepts according to the essence and nature of the represented referent. According to definitions given in dictionaries of linguistic terms: "a category in cognitive linguistics is one of the cognitive forms of human thinking that generalizes experience and classifies it" [Zherebilo, 2010, p. 142]; a language category in a broad sense is any group of language elements that is distinguished on the basis of a common property..." [Linguistic encyclopedia]. In this regard, in terminology, the category is understood as "several typical groups of concepts that usually receive a terminological expression in technology" [Kandelaki, 1970, p. 4], including a Natural object, Substance, Tool, Process, Characteristics, etc. Vertexes that are connected by different types of system relations are presented as adjacent in the database. Two such vertexes that belong to different categories and are linked by a specific type of system relationships represent a more complex element of the terminology network.

In this case, each vertex can potentially have a different number of adjacent vertexes that it is connected with by one or different types of system relations. Each type of system relationship points up to different nature of relationship between two related concepts, transmitted by terms that can be conditionally designated by the variables $\{\mathrm{X}\}$ and $\{\mathrm{Y}\}$. Knowledge of database for the expert system is accumulated in scientific texts-articles, monographs, dictionaries and other specialized sources, that involves contextual analysis, and can also be obtained directly from experts in the subject area during consultations, that is especially relevant for new fields of knowledge [Razduev, 2018].

Other significant methods in this regard are comparative analysis, method of cognitive (in particular, construction of a terminological network) and computer modeling. Thanks to inclusion of semantic networks as a way of representing knowledge in expert systems, it is possible, on the one hand, to describe rather complex subject areas by selecting connections between objects in the semantic network, and on the other hand - to present a system of knowledge illustratively, argumentatively [Boltunov, Krotov, 2016].

Based on the capabilities of terminology network, we have developed several modes of operation of this expert system. If you have user's rights, these are: "Ask a question" mode, "Compare" mode, "Search by attributes" mode, and "Look in dictionary" mode. If you have administrator rights, the "Editor" mode is available, which allows you to make edits and additions.

\section{RESULTS OF THE RESEARCH}

In the "Editor" mode, the program saves concepts, system connections with related concepts, and information related data to each concept in the database. On the basis of introduced concepts, a network structure is built in the form of a graph, where each added concept represents its separate vertex, connected with other vertices by arcs. In this regard, the editor mode provides subsections for adding concepts, categories, and relationships. One of the important tools in the window of entering a new concept is the presence of substitution columns for selecting the main and additional vertex categories, and within them subcategories that are assigned to each added concept. Only the main category is mandatory for filling, while additional category is optional, since it is specific to a very limited range of concepts and can be assigned in exceptional cases. Below there are the fields "Translation", "Definition", "Example of using in context", where the text is entered or copied.

After saving entered data, it is possible to install system relations with related concepts already entered in the database. Addition of a link is put into practice in a separate window by pushing the corresponding button in the term of a card. This window implements tools for adding a link and fields for searching/entering a concept to establish a system relationship with.

Also there has been a lookup column provided for selecting a type of communication and "Acknowledgement" field to enter a text fragment and 
specialized scientific sources that contains both related terms, verbalization of systemic relations between them and is evidence of connection between them.

In the work of this mode, we use the database of standard formulations of questions and answers for the expert system, in which they are systematized in accordance with the selected types of system relations existing between scientific concepts [Gukosyants, Latu, 2019].

Pushing the "Ask " button, the system processes an issue typed by a user in the search bar and, referring to databases, outputs a specific wording of the answer. In the case of a special type of question, the response wording contains both concepts about which information is requested and the concept to which the question is asked, corresponding to values of the variables $\{\mathrm{X}\}$ and $\{\mathrm{Y}\}$. In the case of a general type of question, the "yes" and "no" particles are output as the answer, followed by the full wording of the answer, which also includes values of both variables. However, if the answer is negative, the wording after the "no" particle contains the correct value of the variable $\{\mathrm{Y}\}$.

The responses generated by the system are displayed in the corresponding field located under the search bar for entering questions. Terms in the response wording that are available in the language registry are represented by links that, when clicked, the user goes to the "Look in a dictionary" mode page, where a card for the corresponding term with its definition and other information opens.

Below the "Response" field is the "cases of usage in the context" field. This field displays the value of the "Confirmation" field that was filled in at the stage of establishing a system relationship between the concept that is the value of the variable $\{X\}$ in the question and the value of the variable $\{\mathrm{Y}\}$ in the response. Below the "usage cases in context" field is the "Learn more" field. It lists the wording of questions that correspond to the relationships that are established for the term that is the value of the variable $\{\mathrm{X}\}$ in the question. When you click on a question, its wording appears in the question entry bar, and the corresponding field displays the wording of the answer.

The main tool of the "Compare" mode is two fields for entering source data: a field for the first term and a field for the second term, which represent the concepts being compared. After entering the source data and clicking the "Compare" button, the system, referring to the database, processes the received request and determines the presence of similarities, differences, and specific features in the two referents by analyzing their system relations with related elements of scientific knowledge.

There is a toolbar that includes a filter by features on the right side of the screen, which is a substitution column where you can select specific attributes that will be used for comparison. You can also select the "Show all", "Show similarities", and "Show differences" options on the toolbar.
The results of the analysis are displayed in the "Similarities and common features" and "Differences and specific features" fields, which are located below the fields for entering the compared concepts. The number of responses in the "Differences and specific features" field varies depending on the number of differences and specific features identified for each concept being compared. The output formulation of a response corresponds to a system relation of a specific type, which is established for both concepts being compared, acting as values of the variable $\{X\}$, but with different adjacent concepts, which act as values of the variable $\{Y\}$ for each of them.

In the "Search by attributes" mode, the search for required information is performed via specifying the specified set of attributes as the source data, which are the vertexes of the terminology network. In this regard, the main tool for this mode is the fields for entering attributes, as well as filters located opposite each field, presenting a substitution column with the ability to select parameters for search. Thus, filtrations can be performed by one or several attributes and parameters. The choice of an attribute type implies limiting the search based on the type of system relationship. The response field below shows the results of data processing. One or more found searchable concepts are provided that there have system relations with related concepts pointed in the attribute fields presented

The "Share an idea" mode is a separate section of the expert system designed to provide feedback between a user and an administrator in cases when the user is an expert in this field of scientific knowledge and can offer valuable clarifications and comments to the content of the expert system's responses. Due to the continuous development of science, this mode is necessary for further improvement of the network model of organizing scientific knowledge and expanding the knowledge base of the expert system.

The user sends a message text using the comment field and the "Send" button, which becomes available to the ontoengineer. After consulting with experts in this field, a decision is made on the need to make additions to the knowledge base.

\section{CONCLUSION}

Thus, based on the network representation of scientific knowledge and linguistic design principles, this expert system is able to analyze user-entered questions of a special type about the concepts of astrophysics and generate short correct answers, identify similarities and differences of knowledge elements, detect necessary knowledge based on initial entered data; it is aimed at a wide range of users (specialists and non-specialists) and can be used both in the process of training and selflearning 
[transliteratsiya nazvaniya], Sovetskaya

\section{REFERENCES}

[1] Ajit, A., Semchenko, P.N. (2013), "Rules-based expert systems", Bulletin of Pacific National University [Ekspertnyye sistemy na osnove pravil", Vestnik TOGU], No 3 (30), pp. 29-40.

[2] Ayusheeva, N.N., Dikikh, A.Yu. (2018), “A model for constructing a semantic network of a scientific text", Modern high technology [Model' postroyeniya semanticheskoy seti nauchnogo teksta", Sovremennyye naukoyemkiye tekhnologii], No 6, pp. 9-13.

[3] Basov, N.V., Vasilkova, V.V. (2014), "Semantic networks of sociological knowledge", Journal of Sociology and Social Anthropology ["Semanticheskiye seti sotsiologicheskogo znaniya", Zhurnal sotsiologii i sotsial'noy antropologii], No 17 (1), pp. 112-137

[4] Boltunov, A.I., Krotov, L.N. (2016), “Application of expert systems for solving information security problems", International Research Journal ["Primeneniye ekspertnykh sistem dlya resheniya zadach informatsionnoy bezopasnosti', Mezhdunarodnyy nauchno-issledovatel'skiy zhurnal], No 9 (51), Part 2, pp. 9-12.

[5] Zherebilo, T.V. (2010), Dictionary of Linguistic Terms [Slovar' lingvisticheskikh terminov], Pilgrim, Nazran, 486 pp.

[6] Kandelaki, T.L. (1970), "Work on streamlining scientific and technical terminology and some linguistic problems that arise in this", Linguistic problems of scientific and technical terminology ["Rabota po uporyadocheniyu nauchno-tekhnicheskoy terminologii i nekotoryye lingvisticheskiye problemy, voznikayushchiye pri etom", Lingvisticheskiye problemy nauchno-tekhnicheskoy terminologii], Nauka, Moscow, pp. 40-53.

[7] Latu, M. N. (2018)," Types of system relations between terms in network models of scientific knowledge organization", Issues of cognitive linguistics ["Tipy sistemnykh otnosheniy mezhdu terminami v setevykh modelyakh organizatsii nauchnogo znaniya", Voprosy kognitivnoy lingvistiki], No 4, pp. 134-142.

[9] Yartseva, V.N. (ed.) (1990), Linguistic Encyclopedic Dictionary [name transliteration], Soviet Encyclopedia, Moscow, available at: http://tapemark.narod.ru/les/ of cognitive linguistics [Lingvisticheskiy entsiklopedicheskiy slovar' entsiklopediya], No 4, pp. 134-142.

[9] Ustalov, D. (2017), "Semantic networks and natural language processing", Open Systems. DBMS [Ustalov, D. (2017), "Semantic networks and natural language processing", Open Systems. DBMS ["Semanticheskiye seti i obrabotka yestestvennogo yazyka", Otkrytyye sistemy. SUBD], No 2, available at: https://www.osp.ru/os/2017/02/13052229/

[10] Ahmed, I.M., Alfonse, M., Aref, M., Salem, A.B.M. (2015), "Reasoning techniques for diabetics expert systems", Procedia Computer Science, Vol. 65, pp. 813-820.

[11] Allemang, D., Hendler, J. (2011), Semantic Web for the Working Ontologist: Effective Modeling in RDFS and OWL 2nd Edition. Morgan Kaufmann, 384 p.

[12] Carley, K.M. (1997), "Extracting team mental models through textual analysis", Journal of Organizational Behavior, Vol. 18, pp. 533-558.

[13] Diesner, J. (2013), "From Texts to Networks: Detecting and Managing the Impact of Methodological Choices for Extracting Network Data from Text Data", Artificial Intelligence, Vol. 27(1), pp. 75-78.

[14] Doerfel, M.L. (1998), "What constitutes semantic network analysis? A comparison of research and methodologies”, Connections, Vol. 21(2), pp. 16-26.

[15] Faber, P., Leon, P., Prieto, J. (2009), "Semantic relations, dynamicity, and terminological knowledge bases", Current Issues in Language Studies, Vol. 1, pp. 1-23.

[16] Grabinger, R.S., Wilson, B.W., Jonassen, D.H. (1990), Building expert systems in training and education, New York, London: Praeger.

[17] Gukosyants, O.Yu., Latu, M.N. (2019), "Some features of query construction in an expert system according to the peculiarities of knowledge structuring (using the domain of nanotechnology as an example)". Vestnik of Saint Petersburg University. Language and Literature, Vol. 16 (4), pp. 638-652. 
Social Sciences (Intcess 2017), Istanbul, 6-8 February

[18] Ignizio, J.P. (1991), Introduction to Expert Systems: The Development and Implementation of RuleBased Expert Systems, McGraw-Hill, Inc.

[19] Latu, M.N. (2017), “Academic concepts organization in semantic networks and its reflection in some structural blocks of definitions", Proceedings of the 4th International Conference on Education and
2017, Turkey, pp. 450-454.

[20] Razduev, A.V. (2018), “Anthropocentric features of scientific-technical term formation (drawing on the example of nanotechnology terms)", Espacios, Vol. 39 (2),

pp.

21-28. 